\title{
MATERNAL MORTALITY AND MORBIDITY DUE TO INDUCED ABORTION IN HYDERABAD
}

\author{
Chandra Madhu-Das and Pushpa Srichand
}

\begin{abstract}
OBJECTIVES: To determine the maternal mortality and morbidity due to induced abortion in our set up.

STUDY DESIGN: Descriptive case series.

SETTING: Department of Obstetrics and Gynaecology (Unit-III) Liaquat University Hospital Hyderabad, Sindh from July 2001 to July 2004.

PATIENTS AND METHODS: Medical records of patients with complications of termination of pregnancy were analyzed retrospectively. All patients with history of induced abortion who presented within $\mathbf{4 0}$ days of termination of unwanted pregnancy were included in study. Patients with habitual or spontaneous abortion or who were admitted after $\mathbf{4 0}$ days of induced abortion were excluded.

RESULTS: During study period, total admissions in this unit were 3015. Among these, 498 patients presented with different types of abortion. Of these 498 patients, 32(6.42\%) presented with history of complication of induced abortion and were included in study. Among these cases, 21(65.6\%) patients were in age group 20-40 years; 9(28.12\%) below 20 years and 2 $(6.25 \%)$ above 40 years. Nine $(28.12 \%)$ patients were primigravidae, $4(12.5 \%)$ multipara while 19 $(59.37 \%)$ were grand multipara. Twenty-four $(75 \%)$ patients were admitted with sepsis, 5(15.62\%) with visceral injury and $3(9.37 \%)$ with haemorrhage. Ten $(31.25 \%)$ patients underwent hysterectomy due to septic perforated uterus while $7(21.87 \%)$ patients expired due to complications of induced abortion.

CONCLUSION: Induced abortion for termination of unwanted pregnancy is a major cause of maternal morbidity and mortality in our set up.
\end{abstract}

KEY WORDS: Maternal mortality. Maternal morbidity. Termination of pregnancy. Induced abortion.

\section{INTRODUCTION}

Maternal mortality and morbidity reflect the quality of health care provided to women. Global statistics of maternal mortality estimates more than 600,000 deaths every year ${ }^{1}$ and over $99 \%$ of these deaths occur in developing countries which account for about $85 \%$ of world births. ${ }^{2}$ There are 16 episodes of illness for every maternal death. ${ }^{3}$ Women experience more than 50 million health problems annually. Major causes of maternal morbidity and mortality are sepsis, haemorrhage, genital tract trauma, thrombo-embolism and hypertensive disorders of pregnancy. According to World Health Organization estimates, on average 10-20 million women risk their lives annually by subjecting themselves to termination of pregnancy. Abortion is legalized in developed countries. Medical termination in first trimester is legal in India while menstrual regulation in Bangladesh. ${ }^{4}$ In Pakistan, although the contraceptive prevalence rate has increased from $9 \%$ to $24 \% \%^{5}$, yet majority of women is unaware of different contraceptive methods available and induction of abortion is prohibited by law except to save the life of mother. Under the circumstances, many women facing problem of an unwanted pregnancy do resort to induced abortion usually by an unskilled person resulting in serious complications. Different hospital based studies show that maternal mortality due to induced abortion in Pakistan ranges between $10-11 \%$ of all maternal deaths. ${ }^{6}$ The aim of this study was to find out maternal mortality as well as morbidity related to induced abortion for termination of unwanted pregnancy in our set up.

\section{PATIENTS AND METHODS}

This descriptive study was carried out from $15^{\text {th }}$ July 2001 to $14^{\text {th }}$ July 2004 at department of Obstetrics and Gynaecology (Unit III), Liaquat University Hospital, Hyderabad - Sindh. All patients with gestational age less than 22 weeks, with history of induced abortion carried out by skilled or unskilled persons admitted in unit during study period were included. The case records of all patients who either died or developed complications within 40 days of induced abortion for 
unwanted pregnancy during study period were scrutinized. The variables analyzed were age, parity, status of abortionist, type of complication (organ failure, surgical procedure required) and cause of death. Patients with history of habitual or spontaneous abortion or who were admitted after 40 days of induced abortion or who died or suffered illness due to incidental causes were excluded from study. Causes of deaths were based on clinical findings and investigations because post mortem examination was not allowed by relatives. Data were entered into SPSS version 10.0 and analyzed.

\section{RESULTS}

Total 32 patients were included in study, out of which, $65.6 \%$ were in age group of $20-40$ years with grand multipara comprising of $59.37 \%$ (Table I). There were $71.87 \%$ married cases while $28.12 \%$ unmarried. Most of the abortions were carried out by lady doctors (Table II). Among these, 75\% cases were admitted with sepsis, $15.62 \%$ with visceral injuries and $9.37 \%$ with haemorrhage (Table III). In 29 (90.63\%) patients, termination was carried out in private clinics. Twentyseven (84.37\%) patients needed surgery (Table IV). Seven (21.87\%) patients died and the main cause of deaths was sepsis in about 75\% cases (Figure I).

TABLE I:

AGE AND PARITY STATUS OF STUDY SUBJECTS $(n=32)$

\begin{tabular}{|c|c|c|}
\hline Variable & $\begin{array}{c}\text { Number of } \\
\text { Patients }\end{array}$ & Percentage \\
\hline $\begin{array}{c}\text { Age in years } \\
\qquad \begin{aligned}<20 \\
20-40 \\
>40\end{aligned}\end{array}$ & $\begin{array}{l}09 \\
21 \\
02\end{array}$ & $\begin{array}{c}28.12 \% \\
65.6 \% \\
6.25 \%\end{array}$ \\
\hline $\begin{array}{ll}\text { Parity } & \\
& 0 \\
& 2-4 \\
& >5\end{array}$ & $\begin{array}{l}09 \\
04 \\
19\end{array}$ & $\begin{array}{c}28.12 \% \\
12.5 \% \\
59.37 \%\end{array}$ \\
\hline
\end{tabular}

TABLE II:

STATUS OF ABORTIONIST

\begin{tabular}{|l|c|c|}
\hline \multicolumn{1}{|c|}{ Status } & $\begin{array}{c}\text { Number of } \\
\text { Patients }\end{array}$ & Percentage \\
\hline Lady Doctor & 19 & $59.37 \%$ \\
\hline Lady Health Visitor & 10 & $31.25 \%$ \\
\hline $\begin{array}{l}\text { Traditional Birth } \\
\text { Attendant }\end{array}$ & 03 & $9.37 \%$ \\
\hline
\end{tabular}

TABLE III:

TYPE OF COMPLICATION $(n=32)$

\begin{tabular}{|l|c|c|}
\hline \multicolumn{1}{|c|}{ Complication } & $\begin{array}{c}\text { Number of } \\
\text { Patients }\end{array}$ & Percentage \\
\hline Sepsis & 24 & $75 \%$ \\
\hline Visceral injuries & 05 & $15.62 \%$ \\
- Uterine perforation & 03 & $9.37 \%$ \\
- Combine uterine & 02 & $6.25 \%$ \\
+ gut perforation & & \\
\hline Haemorrhage & 03 & $9.37 \%$ \\
\hline
\end{tabular}

TABLE IV:

DISTRIBUTION OF MANAGEMENT OPTIONS IN STUDY SUBJECTS

\begin{tabular}{|l|c|c|}
\hline \multicolumn{1}{|c|}{ Management Option } & $\begin{array}{c}\text { Number of } \\
\text { Patients }\end{array}$ & Percentage \\
\hline SURGERY & 27 & $84.37 \%$ \\
a) Laparotomy & 19 & $59.37 \%$ \\
- Hysterectomy & 10 & $31.25 \%$ \\
- Hysterectomy along & 02 & $6.25 \%$ \\
with gut surgery \\
$\begin{array}{c}\text { Drainage of pus and } \\
\text { peritoneal toilet }\end{array}$ & 07 & $21.87 \%$ \\
\hline b) Colpotomy & 03 & $9.37 \%$ \\
\hline c) Evacuation of uterus & 05 & $15.62 \%$ \\
\hline d) CONSERVATIVE & 05 & $15.62 \%$ \\
\hline
\end{tabular}

FIGURE I:

CAUSATIVE FACTORS FOR DEATHS

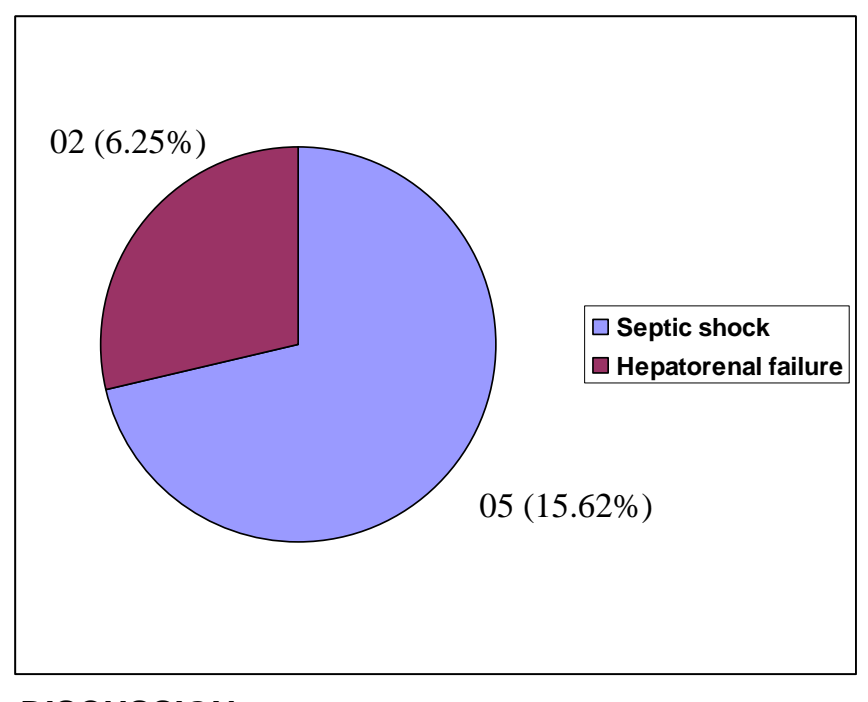

Maternal mortality and morbidity are one of most neglected problems of health care in developing coun- 
tries, where these are 100 times higher than developed countries. Each year, 46 million women around the world undergo abortions. Twenty-six million women who undergo abortion do so in countries with liberal abortion laws. Remaining 20 million undergo abortion in countries where abortion is either restricted or illegal. ${ }^{7}$ According to a World Health Organizations' study in year 2000, one in ten pregnancies ended in unsafe abortion. ${ }^{8}$ Everyday, 55000 unsafe abortions take place, $95 \%$ of them in developing countries. ${ }^{9}$ In developing countries, complications of unsafe abortions cause between 50,000 and 100,000 women's death annually. The proportion of maternal mortality due to abortion related complications range from $8 \%$ in Western Asia to $26 \%$ in South America, with world wide range of $13 \% .{ }^{8}$ Besides, maternal deaths, unsafe abortion can cause serious and long-term damage to women's health. Between $10-50 \%$ women who undergo unsafe abortion, need medical care for complications. ${ }^{9}$ In Pakistan, there is little information available on the rates of abortion including induced abortion. In this society contraception is also scarcely practiced and abortion is illegal, so back street abortions are very common. Frequency of unsafe abortion in current study is $6.42 \%$ while it is reported as $3.06 \%$, $3.08 \%$ and $2.34 \%$ respectively in other studies form different parts of Pakistan. ${ }^{10}$ Meanwhile, it is $2.6 \%$ in Latin America $^{11}$. In present study, majority (65.6\%) of patients was in age group 20-40 years, that is comparable to findings of a study from Karachi, Pakistan. ${ }^{12}$ In current study, $28.12 \%$ women were primigravidae and $59.37 \%$ were grand multigravidae, while Saeed AG from Islamabad, Pakistan has reported $11.55 \%$ patients as primigravidae and $57.8 \%$ multigravidae. ${ }^{11}$ Increased number of multiparae in this study may be due to fact that majority of multigravidae seek advice for termination of unwanted pregnancy but are refused by trained persons and hence, ultimately handled by unskilled workers resulting in death or significant morbidity. In current study, $90.63 \%$ of unsafe abortions were done in private clinics, which is in contrast to a study conducted in Rural India where $46 \%$ of unsafe abortions were done in private clinics. ${ }^{13}$ This is also a fact that majority of private clinics lack properly trained staff and facilities. Most of abortions were performed without anaesthesia. In current study, sepsis was main complication of induced abortion which is in contrast to study carried out by Saeed AG where haemorrhage was the leading complication. Majority of patients (84.38\%) in current study required surgical inter- vention that is comparable with study by Lassey in which $85.7 \%$ patients required surgical intervention. ${ }^{14}$ In our study maternal mortality was $21.87 \%$ which is significantly higher than published data from different hospitals in Pakistan as well as other parts of world such as $10 \%$ in Jinnah Postgraduate Medical Centre Karachi $^{12}, 11.53 \%$ in Gynaecological Department of Federal Government Services Hospital Islamabad ${ }^{10}$, $0.05 \%$ in United States of America ${ }^{8}$ and $2.5 \%$ in Ghana. ${ }^{14}$ This may also be related to the fact that Liaquat University Hospital is a major tertiary care hospital where patients are received in moribund condition from almost all remote areas of Sindh province as well as from all private hospitals of City of Hyderabad. Therefore, government should formulate the policy to help out those women who seek advice for termination of unwanted pregnancy and should catch hold of abortionists and make them accountable for the complications resulting from unsafe abortion. Proper counseling of women coming for antenatal care and delivery in hospitals regarding contraception shall also be done.

\section{REFERENCES}

1. Adam Son P. Deaf to the screams. The Medical Spectrum. 2000; 21:3-5.

2. Bergstron S. Maternal health: a priority in reproductive health. The Medical Spectrum. 1998;19:123-6.

3. Samad M. Safe motherhood initiative. The Medical Spectrum. 1992; 13:12-3.

4. Tinker AG. The World Bank: Women health. Proceedings of the conference. 1998: 1-2.

5. Tinker AG. Reproductive Health Services. The Medical Spectrum. 1998; 19: 129-32.

6. Jafferey S. Preventing maternal deaths due to abortion. Medical Channel. 1998; 4:5-6.

7. AGI - Alan Guttmacher Institute. Facts in Brief: Induced abortion worldwide. New York: Alan Guttmacher Institute.1999.

8. WHO. Unsafe abortion: global and regional estimates of the incidence of unsafe abortion and associated mortality in 2000, $4^{\text {th }}$ Edition. Geneva, Switzerland: World Health Organization. 2004.

9. WHO - World Health Organization. (1998a; accessed 2000, June 16). World Health Day/ Safe Motherhood: Address Unsafe Abortion). Available at http://www.who.int/archives/whday/en/ pages1998/whd98_10.html. 
10. Saeed AG. Complications of induced septic abortions and risk factors. J Coll Physicians Surg Pak. 2002;12:738-40.

11. Ipas (2005a). Achieving ICPD commitments for abortion care in Latin America: The unfinished agenda. Chapel Hill, North Carolina: Ipas.

12. Bhutta SZ, Aziz S, Korejo R. Surgical complications following unsafe abortions. J Pak Med
Assoc. 2003; 53: 286-9.

13. Dhillon BS, Chandhiok N, Kambo I, Saxena NC. Induced abortion and concurrent adoption of contraception in the rural areas of India. Indian J Med Sci. 2004;58: 478-84.

14. Lassey AT. Complications of induced abortions and their prevention in Ghana. East Afr Med J. 1995; 72:774-7.

AUTHOR AFFILIATION:

Dr. Chandra Madhu-Das (Corresponding Author) Senior Medical Officer

Liaquat University Hospital, Hyderabad - Sindh.

Prof. Pushpa Srichand

Department of Obstetrics and Gynaecology

Liaquat University of Medical and Health Sciences

Jamshoro - Sindh. 